F2.1-0042-06

\title{
THE INFLUENCE OF SHIELDING ON THE BIOLOGICAL EFFECTIVENESS OF ACCELERATED PARTICLES FOR THE INDUCTION OF CHROMOSOME DAMAGE
}

\author{
K. George ${ }^{a}$, and F. A. Cucinotta ${ }^{b}$ \\ ${ }^{a}$ Wyle Labs, 1290 Hercules Drive, Houston, TX 77058, USA; \\ Kerry.A.George@nasa.gov \\ ${ }^{b}$ NASA, Lyndon B. Johnson Space Center, NASA Road 1, Houston, TX 77058, USA; \\ Francis.A.Cucinotta@nasa.gov
}

\begin{abstract}
Chromosome damage was assessed in human peripheral blood lymphocytes after in vitro exposure to the either ${ }^{28} \mathrm{Si}$ (490 or $\left.600 \mathrm{MeV} / \mathrm{n}\right),{ }^{48} \mathrm{Ti}(1000 \mathrm{MeV} / \mathrm{n})$, or ${ }^{56} \mathrm{Fe}(600,1000$, or $5000 \mathrm{MeV} / \mathrm{n}$ ). LET values for these ions ranged from 51 to $184 \mathrm{keV} / \mu \mathrm{m}$ and doses ranged from 10 to 200 cGy. The effect of either aluminum or polyethylene shielding on the induction of chromosome aberrations was investigated for each ion. Chromosome exchanges were measured using fluorescence in situ hybridization (FISH) with whole
\end{abstract}


chromosome probes in cells collected at G2 and mitosis in first division post irradiation after chromosomes were prematurely condensed using calyculin-A. The yield of chromosomal aberrations increased linearly with dose and the relative biological effectiveness (RBE) for the primary beams, estimated from the initial slope of the dose response curve for total chromosomal exchanges with respect to $\gamma$-rays, ranged from 9 to 35. The RBE values increased with LET, reaching a maximum for the $600 \mathrm{MeV} / \mathrm{n} \mathrm{Fe}$ ions with LET of $184 \mathrm{keV} / \mu \mathrm{m}$. When the LET of the primary beam was below approximately $100 \mathrm{keV} / \mathrm{\mu m}$, the addition of shielding material increased the effectiveness per unit dose. Whereas shielding decreased the effectiveness per unit dose when the LET of primary beams was higher than $100 \mathrm{keV} / \mu \mathrm{m}$. The yield of aberrations correlated with the dose-average LET of the beam after traversal through the shielding. 


\section{INTRODUCTION}

The radiation environment in outer space is intense and complex, consisting of highenergy protons, and energetic highly charged nuclei (HZE particles), along with secondary radiation including neutrons that are produced by the interactions of primary particles with shielding both from the spacecraft and the human body itself (Wilson et al., 1995). It has been shown that HZE particles have a higher RBE than X-rays or $\gamma$-rays for most endpoints (Cucinotta et al, 2001a; Kawata et al., 2001; Wu et al., 1997; Kiefer et al., 1994; Yang et al., 1985; Alpen et al., 1993). Space radiation is therefore a major concern for human exploration of the solar system and effective radiation shielding is essential to keep astronauts within safe exposure limits. Model calculations are commonly used for designing spacecraft shielding (Wilson et al, 2001), but it is generally acknowledged that physical and especially biological measurements are needed to validate the predictions resulting from these codes.

Chromosomal aberrations have been used in mechanistic studies of radiation effects, in biodosimetry, and as possible biomarkers for carcinogenesis. It has been shown that the frequency of chromosome aberrations increases in astronauts blood lymphocytes after space flight (George et al., 2001 a and b; Federenko et al., 2001; Durante et al., 2003), and results indicate that biodosimetry estimates lie within the range expected from physical dosimetry and ICRP models, when samples are obtained shortly after flight (George et al., 2001 a).

Several studies have reported data on chromosome aberrations induced in human cells by in vitro exposure to accelerated protons and heavy ions, and these studies indicate that the linear coefficients for the induction of aberrations increase with LET, 
peaking around 60-100 keV/ $\mu \mathrm{m}$, and decrease sharply at higher LET (Durante et al., 2005; George et al., 2002; George et al., 2003). It has been shown, using FISH painting, that high-LET radiation is more efficient than $\gamma$-rays or X-rays at inducing complex chromosome rearrangements involving the interaction of three or more chromosome breaks and the rearrangements were of greater complexity (Durante et al., 2002; George et al., 2003). However, cell cycle delays must be considered when comparing results for low- and high- LET. High-LET induced chromosome exchanges can undergo a significant G2-M phase cell cycle delay, which hinders their progression into mitosis. Presumably this is due to the non homogenous nature of the energy deposition, which is focused along a particle track. Cells hit by the particle track can be heavily damaged and severe cell cycle delay or interphase cell death can result, whereas other cells with no hits will progress normally through the cell-cycle (George et al., 2001 c; Nasonova et al., 2001; Scholz et al., 1998; Ritter et al., 2000; Durante et al., 1999). This is in contrast to low-LET radiation exposures, such as gamma rays, where a more even distribution of damage could induce a uniform distribution of cell-cycle delays. Therefore, the selection of cell population is extremely important to avoid bias. Analysis of chemically induced PCC from the G2 and metaphase stages of the cell cycle has been shown to reduce the population selection bias in metaphase, and analysis of PCC results in considerably higher RBE values (George et al., 2001 c ).

\section{MATERIALS AND METHODS}

These studies were conducted in accordance with accepted ethical and humane practices,

and were approved by the appropriate institutional and/or governmental committee(s) and/or 
organization(s).

\section{$\underline{\text { Irradiation }}$}

Whole blood was collected from healthy volunteers and irradiated with $\gamma$-rays or accelerated heavy ions. In most cases one volunteer was used for the study of each ion, and involved a different person in most cases. The $1 \mathrm{GeV} / \mathrm{n}$ Fe and $600 \mathrm{MeV} / \mathrm{n}$ Si studies were repeated and no significant difference was detected in the dose response data so values were combined. Values for all other beams represent data from one experiment. A summary of the beam characteristics and shielding data for each experiment is provided in table 1 . The $490 \mathrm{MeV} / \mathrm{n}$ silicon beam was generated at the Heavy Ion Medical Accelerator at Chiba (HIMAC) in the National Institute of Radiological Sciences (NIRS) in Chiba, Japan. All other beams were generated at Brookhaven National Laboratory, N.Y. using the Alternating Gradient Synchrotron (AGS) or the NASA Space Radiation Laboratory (NSRL) facilities. The target area was shielded with blocks of polyethylene or aluminum. All the doses described here represent the dose at the sample location and these doses were measured using ionization chambers. The exposures with the addition of shielding were adjusted to generate the same dose to the sample as the unshielded samples.

Dose-average LET’s were estimated using the High Energy and Charge Transfer (HZETRN) computer code, which is excellent agreement with other codes for estimating LET from heavy ions (Cucinotta et al., 2001b). For the heavy ions, dose-rates were between 0.2 and $0.5 \mathrm{~Gy} / \mathrm{min}$ varying depending on the dose delivered. Each sample received at least 3 pulses and no exposure lasted more than 10 minutes. X-ray films were 
exposed to check the beam uniformity and dose did not vary more than $5 \%$ over the target area. Further details on the irradiation set up and procedures are outlined in the references (Zeitlin et al., 1998; Kanai et al., 1999).

For comparison we used a dose-response curve measured with gamma-rays, at a dose rate of approximately $1 \mathrm{~Gy} / \mathrm{min}$. Samples were exposed at room temperature in 15 $\mathrm{ml}$ polystyrene centrifuge tubes with a $1.45 \mathrm{~cm}$ opening for the sample and $1.4 \mathrm{~mm}$ wall thickness between the beam line and the sample. No buildup or backscatter material was used during the exposures. For exposure to heavy ions, the blood was placed in specially designed polyethylene holders with a $1 \mathrm{~mm}$ thick well for the sample and $2 \mathrm{~mm}$ of polyethylene between the sample and the beam line. The shield material was placed between the beam and the blood holder Doses were measured at the target using ionization chambers.

\section{Cell culture}

Immediately after exposure, whole blood cultures containing RPMI 1640 media (Gibco BRL) supplemented with 20\% calf serum, and 1\% phytohemagglutinin (Gibco, $\mathrm{BRL}$ ) were incubated at $37^{\circ} \mathrm{C}$. Chemically induced PPC were collected $48-56$ hours later using the method described by Durante et al. (1999), which results in well condensed chromosomes from cells in G2 and metaphase. Briefly, $50 \mathrm{nM}$ calyculin A (Wako Chemicals) was added to the growth media for the last 30 minutes of the incubation. Cells were then treated with hypotonic $\mathrm{KCl}(0.075 \mathrm{M})$ for 15 minutes at $37^{\circ} \mathrm{C}$ and fixed in methanol:acetic acid (3:1).

A $0.5 \mathrm{ml}$ volume of blood from each sample was cultured with $10 \mu \mathrm{m}$ bromodeoxyuridine (BrdU), metaphase cells were collected using established harvesting 
procedures and differential replication staining procedure was completed on chromosomes from these samples by incubating slides in $0.5 \mathrm{mg} / \mathrm{ml}$ of Hoescht during exposure to black light (General Electric 15T8/BL bulb). Chromosome preparations were stained with Giemsa to visualized replication rounds. Percentage of cells in first mitosis was greater than $90 \%$ for all samples analyzed.

\section{$\underline{\text { FISH }}$}

Chromosome spreads were dropped onto clean microscope slides, aged overnight at $40^{\circ} \mathrm{C}$, and hybridized in situ with a combination of two fluorescence whole chromosome human DNA probes (Vysis, Downers Grove, IL), following the protocol recommended by the manufacturer. Each chromosome pair was labeled using different color fluorophores and unlabelled chromosomes were always counterstained with 4,6diamidino-2-phenylindole (DAPI). Chromosomes 1 and 3 were analyzed in the $490 \mathrm{MeV}$ silicon irradiated cells, and for all other samples chromosomes 1 and 2 were analyzed. For direct comparison of all results, data was extrapolated to whole genome equivalents using the statistical procedure outlined below.

\section{Chromosome analysis}

Chromosomes were analyzed on an epi-fluorescent Axioplan microscope (Carl Zeiss, Germany). The images of all damaged cells were captured electronically using a CCD camera and the cytovision software from Applied Imaging. All slides analyzed in this study were coded and scored blind. Chromosome damage was assessed in cells where the chromosomes were well spread, well painted, and appeared to be intact. An 
exchange was scored as a complex if it was determined that it involved a minimum of three breaks in two or more chromosomes. An exchange was defined as simple if it appeared to involve two breaks in two chromosomes, i.e. dicentrics and translocations or incomplete translocations and incomplete dicentrics. Each type of exchange i.e. dicentrics, simple reciprocal exchanges, incompletes, or complex exchanges, was counted as one exchange. When two or more painted chromosomes were damaged, each was scored separately. Values for total exchanges were derived by adding the yields of complex and simple exchanges. Background frequencies of exchanges were assessed for each data set and values were subtracted from dose response data. The exact number of control cells analyzed varied between studies, the average being around 800 cells. The background frequency varied from 0.6 - 1.6 exchanges per 100 cells, whole genome equivalent.

\section{$\underline{\text { Statistical analysis }}$}

The frequencies of chromosomal aberrations in the painted chromosome(s) were evaluated as the ratio between aberrations scored and total cells analyzed. A different combination of chromosomes were analyzed in one study (490 MeV Si) and for a direct comparison of data, the frequencies of exchanges in individual chromosomes were extrapolated to whole genome equivalents using a modified version of the Lucas et al. (1992) formula, $F p=2.05[f p(1-f p)+f p 1 f p 2+f p 1 f p 3+f p 2 f p 3\} F G$. Fp is the combined frequency of exchanges in all painted chromosomes, fp is the fraction of the whole genome comprised of the painted chromosomes, fp1, fp2, and fp3 are the fractions of the genome for each individual chromosome. 
Standard errors for aberration frequencies were calculated assuming Poisson statistics. Error bars in each figure represent standard errors of the mean values. For estimates of initial slopes or $\mathrm{RBE}_{\max }$, the background-rates for aberration formation were subtracted from each curve, and the errors from this subtraction included in further analysis. The weighted regression model was used to estimate a linear fit to the data for each radiation type. Calculations of $\mathrm{RBE}_{\max }$ were then estimated from the alpha component of the each linear fit.

\section{RESULTS}

A comparison of the dose-response curves for the induction of total interchromosomal exchanges induced by unshielded beams is shown in Figure 1. Although no shield blocks were placed on the beam line, these beams should not be considered as "pure" iron beams as some fragments are produced by beam interaction with scatterers, monitors, exit windows, air, etc. The yield of chromosomal aberrations increased linearly with dose for all ions studied. In figure 2 the alpha components of each dose response curve are plotted against respective LET for the ion. Figure 2 includes data for additional ions from a previous published study where data was collected using the same methods (George et al., 2003) and data from a $290 \mathrm{MeV} / \mathrm{n}$ carbon irradiation. This additional data gives a more comprehensive comparison for wider range of LET values. The alpha component increases with LET and peaks for the $600 \mathrm{GeV} / \mathrm{n}$ iron ions with LET of $184 \mathrm{keV} / \mu \mathrm{m}$, then values decrease sharply at higher LET. 
The frequencies of total chromosome exchanges induced by the unshielded and shielded beams are plotted separately for each ion in figure 3. For both the 490 and 600 $\mathrm{MeV} / \mathrm{n}$ silicon beams (LET 56 and $51 \mathrm{keV} / \mu \mathrm{m}$, respectively) the addition of most types of the shielding material increased the yield of exchanges. However, the $5 \mathrm{~cm}$ polyethylene shielding had no effect on the yield of exchanges induced by $600 \mathrm{MeV} / \mathrm{n} \mathrm{Si}$ ion beam when values were compared with the same unshielded beam, and the yield was only slightly reduced by the addition of $15 \mathrm{~cm}$ polyethylene shielding. However, $20 \mathrm{~g} / \mathrm{cm}^{2}$ aluminum shielding significantly increased the yield of exchanges induced by the 600 $\mathrm{MeV} / \mathrm{n}$ Si beam. For all the other beams studied (600 MeV/n, $1 \mathrm{GeV} / \mathrm{n}$, and $5 \mathrm{GeV} / \mathrm{n}$ iron, and $1 \mathrm{GeV} / \mathrm{n} \mathrm{Ti}$; LET range of 108 to $184 \mathrm{keV} / \mu \mathrm{m}$ ) the addition of shielding decreased the yield of exchanges. The most significant decrease in the yield was seen when comparing the unshielded and the aluminum shielded $600 \mathrm{MeV} / \mathrm{n}$ iron beam. Here the values decreased approximately four fold when the shielding was introduced. In some cases the dose reponse curves for the shielded samples appeared to have a linear quadratic reponse. All the curves in figure 3 are fitted with a weighted linear regression fit. This type of curve fitting favors the low dose points because more cells were analyzed for these data points. Table 1 lists all the alpha components of the curve fitting for the chromosome exchanges plots induced by both the shielded and unshielded beams.

In figure $4 \mathrm{RBE}$ values for induction of total chromosome exchanges are plotted against the dose-average LET values. The unshielded data is represented by the white symbols and the shielded data by the black symbols. The RBE seems to correlate quite well with this measure of LET and response is similar for shielded and unshielded beams. 


\section{DISCUSSION}

In the present study we have reported the biological effectiveness of several highLET ions and assessed the influence of shielding. The yield of total chromosomal exchanges in human peripheral blood lymphocytes were examined as a function of the dose at the sample position. The RBE for the primary ${ }^{28} \mathrm{Si}$ (490 or $600 \mathrm{MeV} / \mathrm{n}$ ), ${ }^{48} \mathrm{Ti}$ (1000 MeV/n), or ${ }^{56} \mathrm{Fe}(600,1000$, or $5000 \mathrm{MeV} / \mathrm{n})$ beams, estimated with respect to $\gamma$ rays, ranged from 9 to 35. The RBE values increased with LET, and in the present study they reached a maximum for the $600 \mathrm{MeV} / \mathrm{n}$ iron ions with LET of $184 \mathrm{keV} / \mu \mathrm{m}$, and decreased with further increase in LET. This RBE/LET trend is consistent with other published studies of chromosome damage (Durante et al., 2005; George et al., 2003) and other biological endpoints, i.e. transformation (Yang et al., 1985), cell survival (Furusawa et al., 2000), and mutations (Kiefer et al., 1994). In the present study 600 $\mathrm{MeV} / \mathrm{n}$ Fe ions were the most effective at inducing chromosome damage. This is a little surprising as previous studies indicate that $1 \mathrm{GeV} / \mathrm{n}$ Fe ions produce the highest RBE values (Durante et al., 2005; George et al., 2003). In fact our RBE value for the unshielded $600 \mathrm{MeV} / \mathrm{n}$ Fe does not seem to fit the RBE/LET trend seen for the other ions (figure 4). We generated the $600 \mathrm{MeV}$ iron data from only one irradiation study, and we plan to repeat these exposures to determine if the results presented here are an anomaly.

Sour results indicate that shielding increased the effectiveness per unit dose when the primary beam was below $100 \mathrm{keV} / \mu \mathrm{m}$. Whereas shielding decreased the effectiveness per unit dose when the LET of the primary particle beam was higher than $100 \mathrm{keV} / \mu \mathrm{m}$. Shielding modifies the quality of the primary beam causing fragmentation and samples behind the shield are exposed to a mixed radiation field that includes fast projectile 
fragments and neutrons. For the beams studied here the mean free path for fragmentation in water ranges from $161 \mathrm{~mm}^{2}$ (for $490 \mathrm{MeV} / \mathrm{n} \mathrm{Si}$ ) to $1780 \mathrm{~mm}^{2}$ (for $5 \mathrm{GeV} / \mathrm{n}$ iron), as shown in table 1 . For the $490 \mathrm{MeV} / \mathrm{n}$ and the $600 \mathrm{MeV} / \mathrm{n}$ Si beams, only a few of primary silicon ions will survive to reach the target and for these beams nuclear fragmentation dominants behind the shield. The dose behind the shield is lower than the dose hitting the shield, and results in an increased dose-average LET. The fluence incident on the shield has to be increased to keep the dose at the target the same as that of the unshielded samples, and more biological damage will be produced as consequence of the dose is higher.

For the other beams in the present study $(600 \mathrm{MeV} / \mathrm{n}, 1 \mathrm{GeV} / \mathrm{n}$, and $5 \mathrm{GeV} / \mathrm{n}$ iron, and $1 \mathrm{GeV} / \mathrm{n} \mathrm{Ti}$ ), the increase in LET caused by the slow-down of the primary ion as it traverses the shielding material compensates fragmentation, and the Bragg curve increases with thickness. The opposite effect occurs in comparison with the silicon beams; the dose behind the shield is higher than the dose hitting the shield, and the dose average LET decreases. The fluence incident on the shield has to be decreased to keep the dose at the target the same as that of the unshielded samples. Therefore the decreased dose results in less biological damage. This effect has been described previously by Zetlin et al. (1998).

Results from the present study support previous work by Durante el at (2005) who studied the influence of various shielding materials on cytogenetic effects induced by four different energies of Fe ions. However, Durante et al, found that RBE for the induction of chromosome aberrations did not correlate well with dose-average LET. In 
the present study however, the RBE values for the shielded and unshielded beams seem to correlate quite well with the dose-average LET values.

The results from the present study demonstrate that biological effects are determined by both physical beam transport through the shielding and biological effectiveness of the mixed charged-particle radiation field.

\section{ACKNOWLEDGMENTS}

The authors are grateful to the staff of the Brookhaven National Laboratory and NIRS for supporting the runs.

\section{REFERENCES}

Alpen, E.L., Powers-Risius, P., Curtis, S.B., and DeGuzman, R., Tumorigenic Potential of High-Z, High-LET Charged Particle Radiations. Radiat. Res., 88, 132-143, 1993.

Cucinotta, F.A., Manuel, F., Jones, J., Izsard, G., Murrey, J., Djojonegoro, B., and Wear, M., Space radiation and cataracts in astronauts. Radiat. Res., 156, 460-466, 2001a . Cucinotta, F.A., Schimmerling, W., Wilson, J.W., Peterson, L.E., Badhwar, G.D., Saganti, P., and Dicello, J.F., Space radiation cancer risks and uncertainties for Mars missions. Radiat. Res., 156, 682-688, 2001 b.

Durante, M. George, K. Gialanella, G., Grossi, G., La Tessa, C., Manti, L., Miller, J., Pugliese, M., Sampoli, P., and Cucinotta, F.A, Cytogenetic effects of high-energy iron ions: dependence on shielding thickness and material. Radiat Res., 571-576, 2005. 
Durante, M., Snigiryova, G., Akaeva, E., Bogomazova, A., Druzhinin, S., Fedorenko, B., Greco, O., Novitskaya, N., Rubanovich, A., Shevchenko, V., von Recklinghausen, U., and Obe, G., Chromosome aberration dosimetry in cosmonauts after single or multiple space flights. Cytogenet. Genome Res., 103, 40-46, 2003.

Durante, M., George, K., Wu H., and Cucinotta, F.A., Karyotypes of Human

Lymphocytes Exposed to High-Energy Iron Ions. Radiat. Res., 158, 581-590, 2002.

Durante, M., Furusawa, Y., Majima, H., Kawata, T., and Gotoh, E., Association between G2-phase block and repair of radiation-induced chromosome fragments in human lymphocytes. Radiat. Res., 151, 670-676, 1999.

Fedorenko, B.S., Druzhinin, S., Yudaeva, L., Petrov, V., Akatov, T., Snigiryova, G., Novitskaya, N., Shevchenko, V., and Rubanovich, A., Cytogenetic studies of blood lymphocytes from cosmonauts after long-term space flights on Mir station. Adv. Space Res., 27, 355-359, 2001.

Furusawa, Y., Fukutsu, K., Aoki, M., Itsukaichi, H., Eguchi-Kasai, K., Ohara, H., Yatagai, F., Kanai, T., and Ando, A., Inactivation of aerobic and hypoxic cells from three different cell lines by accelerated (3)He-, (12)C- (20)Ne-ion beams. Radiat. Res., 154, 485-496, 2000.

George, K., Durante, M., Wu, H., Willingham, V., Badhwar, G., and Cucinotta, F.A., Chromosome aberrations in the blood lymphocytes of astronauts after space flight. Radiat. Res., 156, 731-738, 2001 a.

George, K., Wu, H., Willingham, V., and Cucinotta, F.A., The effect of space radiation on the induction of chromosome damage. Phys. Med., 17, S222-S225, 2001 b. 
George, K., Wu, H., Willingham, V., Furusawa, Y., Kawata, T., and Cucinotta, F.A., High- and low-LET induced chromosome damage in human lymphocytes; a time course of aberrations in metaphase and interphase. Int. J. Radiat. Biol., 77, 175-183, 2001 c.

George, K., Willingham, V., Wu, H., Gridley, D., Nelson, G., and Cucinotta, F.A., Chromosome aberrations in human lymphocytes induced by $250 \mathrm{MeV}$ protons: effects of dose, dose rate and shielding. Adv. Space Res., 30, 891-899, 2002.

George, K., Durante, M., Willingham, V., Wu, H., Yang T.C., and Cucinotta, F.A., Biological effectiveness of accelerated particles for the induction of chromosome damage measured in metaphase and interphase in human lymphocytes. Radiat. Res., 160, 425-435, 2003.

Kanai, T. Endo, M., Minohara, S., Miyahara, N., Koyama-ito, H., Tomura, H., Matsufuji, N., Futami, Y., Fukumura, A., Hiraoka, T., Furusawa, Y., Ando, K., Suzufi, M., Soga, F., and Kawachi, K., Biophyisical characteristics of HIMAC clinical irradiation system for heavy-ion radiation therapy. Int J Radiat. Oncol. Biol. Phys., 44, 201-210, 1999.

Kawata, T., Durante, M., Furusawa, Y., George, K., Takai, N., Wu, H., and Cucinotta, F.A.,. Dose-response of initial G2-chromatid breaks induced in normal human fibroblasts by heavy ions. Int J Radiat Biol,. 77(2), 165-174, 2001.

Kiefer, J., Stoll U., and Schneider, E., Mutation induction by heavy ions. Adv. Space Res., 14, 257-265, 1994. 
Lucas, J.M., Poggensee, M., and Straume, T., The persistence of chromosome translocations in a radiation worker accidentally exposed to tritium. Cytogenet. Cell Genet., 60, 255-6, 1992.

Nasonova, E. ,Ritter, S., Gudowska-Nowak, E., and Kraft, G., High-LET-induced chromosomal damage: time-dependent expression. Physica Medica, 17, 198-201, 2001.

Ritter, S., Nasonova, E., Gudowska-Nowak, E., Scholz, M., and Kraft, G., High-LETinduced chromosome aberrations in V79 cells analyzed in first and second postirradiation metaphases. Int J Radiat. Biol., 76, 149-161, 2000.

Scholz, M., Ritter, S., and Kraft, G., Analysis of chromosome damage based on the time course of aberrations. Int. J. Radiat. Biol., 74, 325-331, 1998.

Wilson, J.W., Cucinotta, F.A., Kim, M., and Schimmerling, W., Optimized shielding for space radiation protection. Phys. Med., 17, S67-S71, 2001.

Wilson, J.A., Thibeault, S.A., Cucinotta, F.A., Shinn J.L., Kim, M., Kiefer R., and Badavi, F.F., Issues in protection from galactic cosmic rays. Radiat. Environ. Biophys., 34, 217-222, 1995.

Wu, H., Durante, M., George, K., and Yang, T.C., Induction of chromosome aberrations in human cells by charged particles. Radiat. Res., 148, S102-107, 1997.

Yang, T.C., Craise, L.M., Mei M.T., and Tobias, C.A., Neoplastic cell transformation by heavy charged particles. Radiat. Res., 104, S177-187, 1985. 
Zeitlin, C., Heilbronn, L., and Miller, J., Detailed characterization of the 1087 $\mathrm{MeV} /$ nucleon iron-56 beam used for radiobiology at the alternating gradient synchrotron. Radiat. Res., 149, 560-569, 1998. 
Table 1. Summary of the ion beams.

\begin{tabular}{|c|c|c|c|c|c|c|c|}
\hline Ion & $\begin{array}{l}\text { Energy }^{1} \\
\text { (MeV/n) }\end{array}$ & $\begin{array}{l}\text { Range }^{2} \\
(\mathrm{~mm})\end{array}$ & $\begin{array}{l}\text { Shield } \\
\text { material }^{3}\end{array}$ & $\begin{array}{l}\text { Shield } \\
\text { thickness } \\
\text { (mm) }\end{array}$ & $\begin{array}{l}\text { Shield } \\
\text { thickness } \\
\left(\mathrm{g} / \mathrm{cm}^{2}\right)\end{array}$ & $\begin{array}{l}<\mathrm{LET}>_{\text {Dose }} \\
,(\mathrm{keV} / \mu \mathrm{m})\end{array}$ & $\alpha \quad 1 /$ cGy-eq \\
\hline${ }^{28} \mathrm{Si}$ & 490 & 161 & - & - & - & 56 & $0.78 \pm 0.04$ \\
\hline${ }^{28} \mathrm{Si}$ & 490 & 43 & Polyethylene & 120 & - & 81 & $0.95 \pm 0.03$ \\
\hline${ }^{28} \mathrm{Si}$ & 600 & 220 & - & - & - & 51 & $0.60 \pm 0.03$ \\
\hline${ }^{28} \mathrm{Si}$ & 600 & 166 & Polyethylene & 50 & - & 57 & $0.55 \pm 0.02$ \\
\hline${ }^{28} \mathrm{Si}$ & 600 & 73 & Polyethylene & 150 & - & 78 & $0.64 \pm 0.03$ \\
\hline${ }^{28} \mathrm{Si}$ & 600 & 63 & Aluminum & - & 20 & 70 & $1.05 \pm 0.05$ \\
\hline${ }^{{ }^{8} \mathrm{Ti}}$ & 1000 & 321 & - & - & - & 108 & $1.21 \pm 0.05$ \\
\hline${ }^{48} \mathrm{Ti}$ & 1000 & 117 & Polyethylene & 200 & - & 90 & $0.96 \pm 0.05$ \\
\hline${ }^{56} \mathrm{Fe}$ & 600 & 128 & - & - & - & 184 & $1.52 \pm 0.08$ \\
\hline${ }^{56} \mathrm{Fe}$ & 600 & 17 & Aluminum & - & 14 & 210 & $0.37 \pm 0.03$ \\
\hline${ }^{56} \mathrm{Fe}$ & 1000 & 290 & - & - & - & 151 & $1.38 \pm 0.05$ \\
\hline${ }^{56} \mathrm{Fe}$ & 1000 & 171 & Polyethylene & 100 & - & 140 & $0.97 \pm 0.03$ \\
\hline${ }^{56} \mathrm{Fe}$ & 5000 & 1780 & - & - & - & 148 & $1.00 \pm 0.04$ \\
\hline${ }^{56} \mathrm{Fe}$ & 5000 & 1749 & Polyethylene & 100 & - & 142 & $0.80 \pm 0.04$ \\
\hline${ }^{56} \mathrm{Fe}$ & 5000 & 1653 & Polyethylene & 200 & - & 160 & $0.74 \pm 0.04$ \\
\hline
\end{tabular}

1. Acceleration energy in vacuum

2. Residual range in water of the primary ions calculated at the sample position. 
Figure 1. Dose response curves for induction of chromosome aberrations induced by unshielded ions. Values represent total whole genome equivalent values for total interchromosomal exchanges. Gamma dose response data is included for comparison

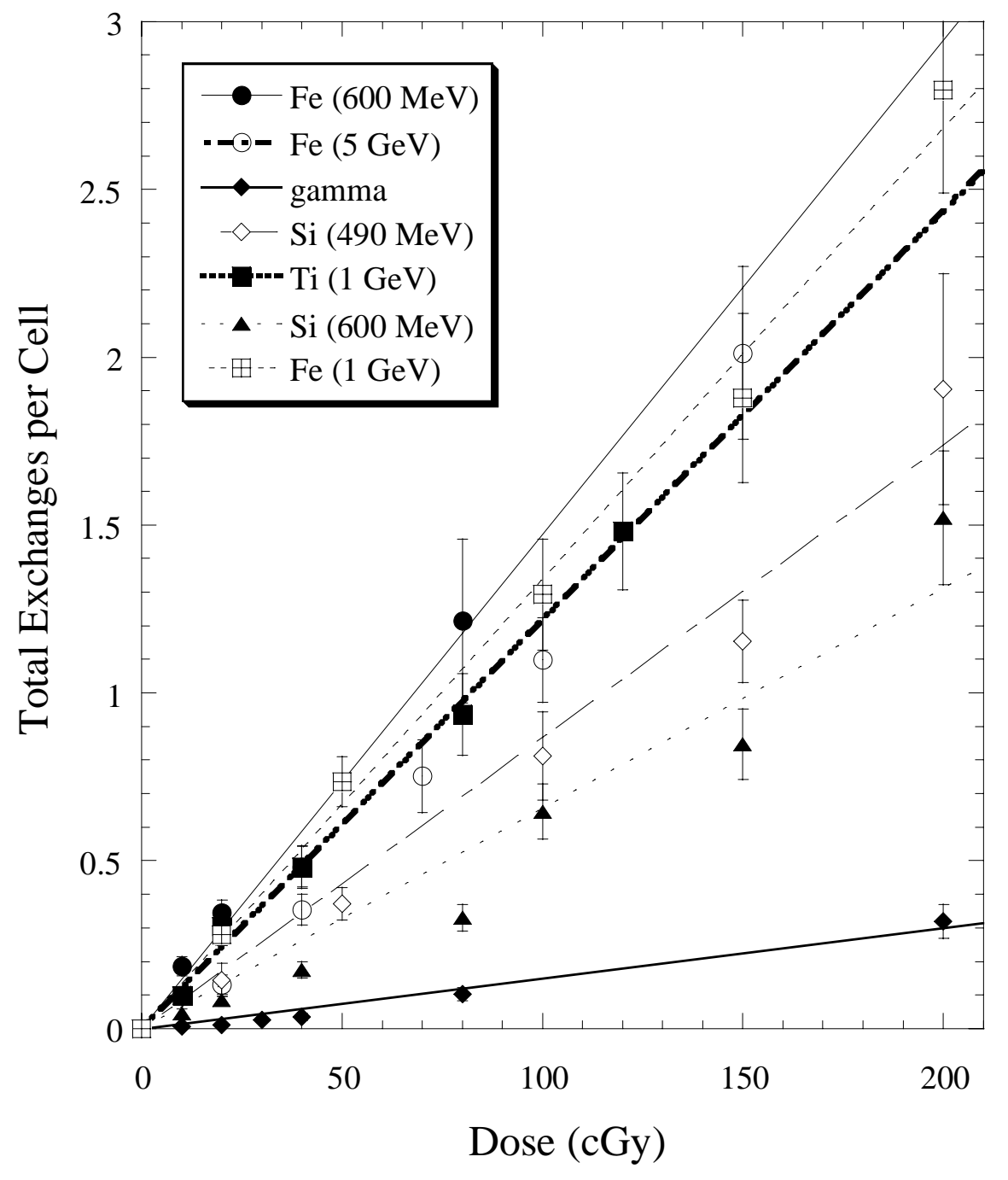


Figure 2. The alpha component of the dose response curve for each unshielded ion beam plotted against the LET value for the ion. Data also includes values obtained from unshielded $200 \mathrm{MeV} / \mathrm{n}$ iron ions (LET $440 \mathrm{keV} / \mu \mathrm{m}$ ) and $500 \mathrm{MeV} / \mathrm{n}$ iron ions (LET 200 $\mathrm{keV} / \mu \mathrm{m})($ published in George et al., 2003) and $290 \mathrm{MeV} / \mathrm{n}$ carbon, which gives a comparison of a wider LET range.

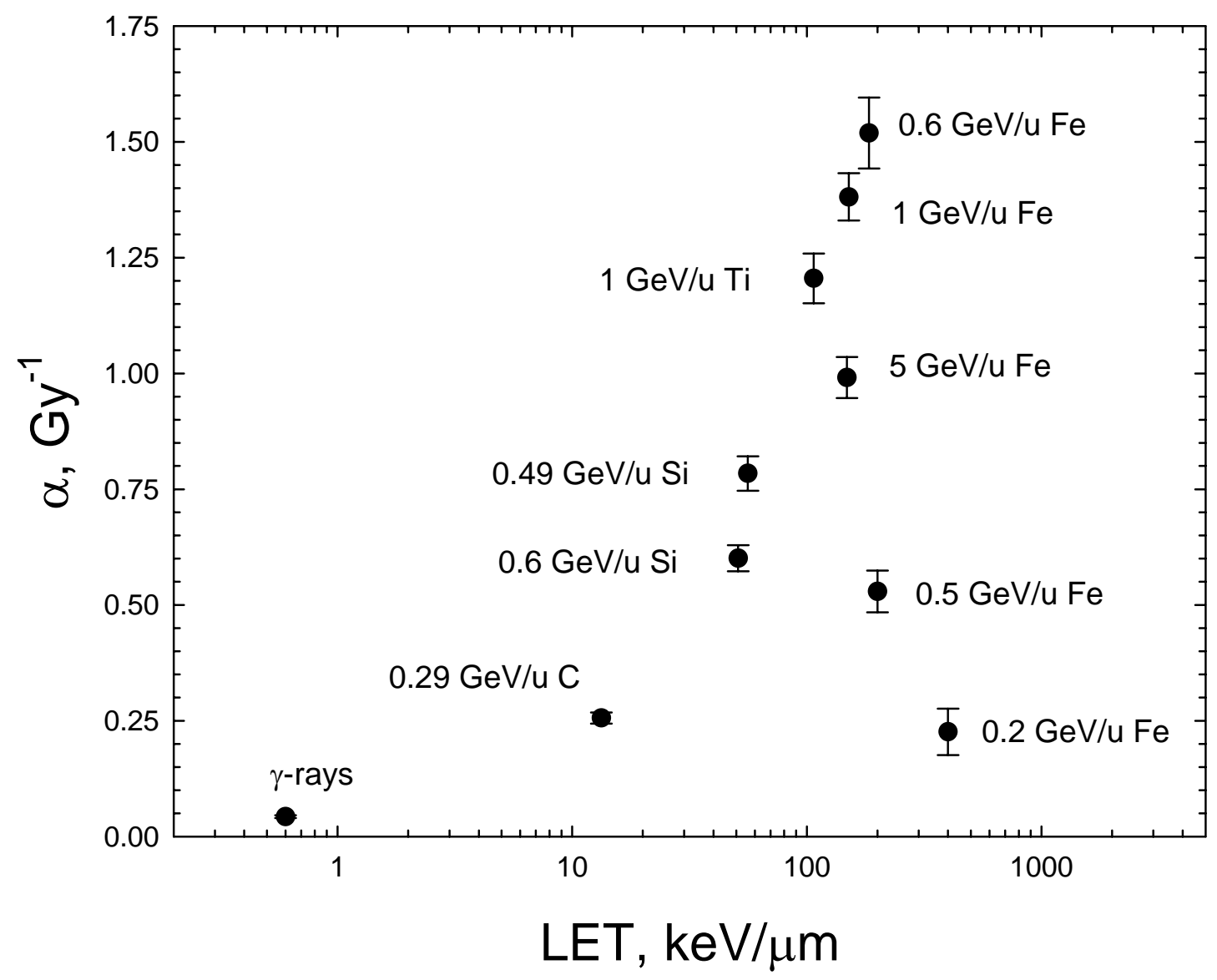




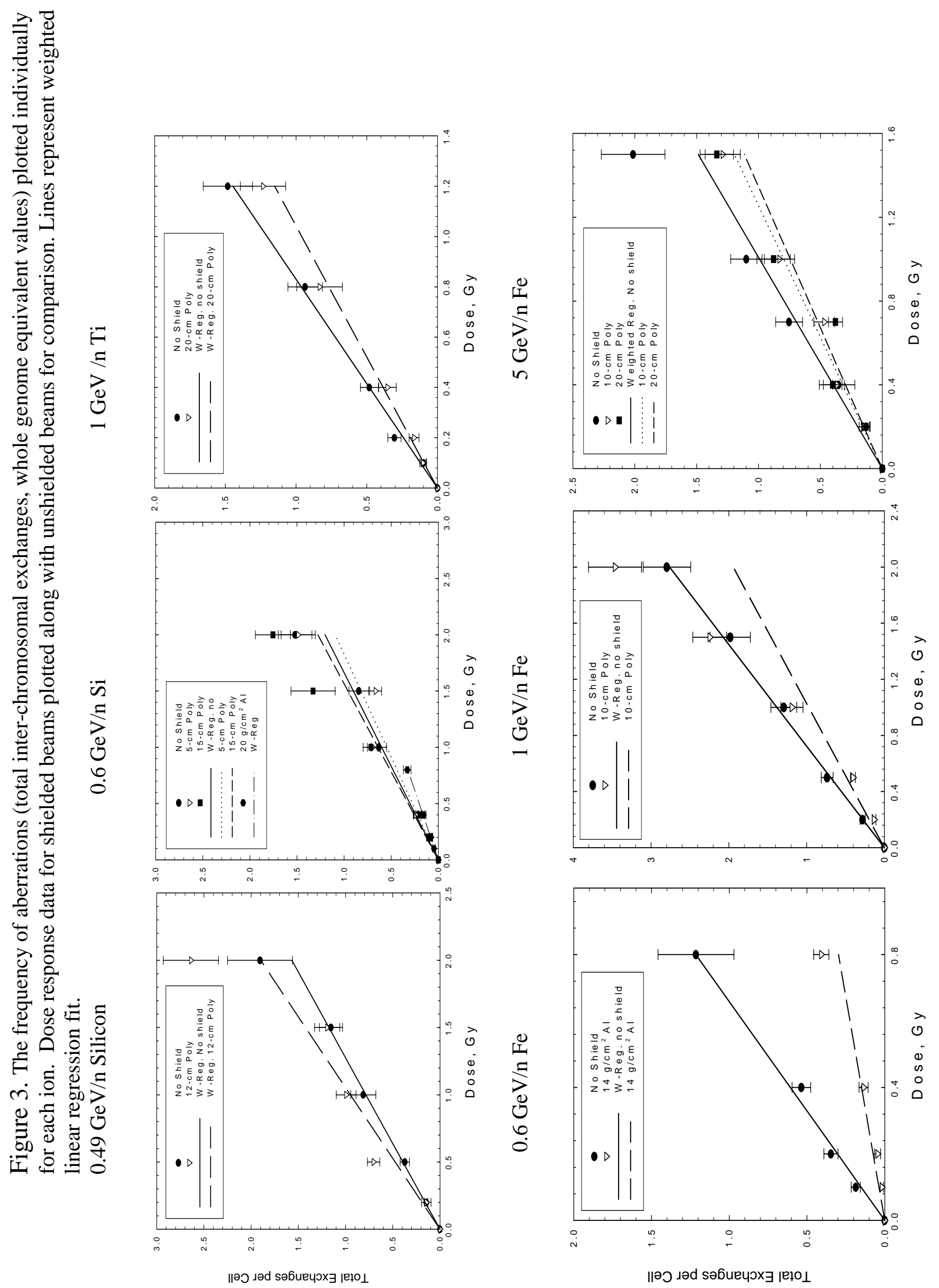


Figure 4. RBE for each ion plotted against the dose-average LET. The white symbols represent values obtained from the unshielded cells and the black symbols represent the values obtained from the shielded cells. Plot also includes unshielded $200 \mathrm{MeV} / \mathrm{n}$ iron ions (LET $440 \mathrm{keV} / \mu \mathrm{m}$ ), $500 \mathrm{MeV} / \mathrm{n}$ iron ions (LET $200 \mathrm{keV} / \mu \mathrm{m}$ ), $290 \mathrm{MeV} / \mathrm{n}$ carbon ions (LET $13 \mathrm{keV} / \mu \mathrm{m})$, which gives a comparison of a wider LET range.

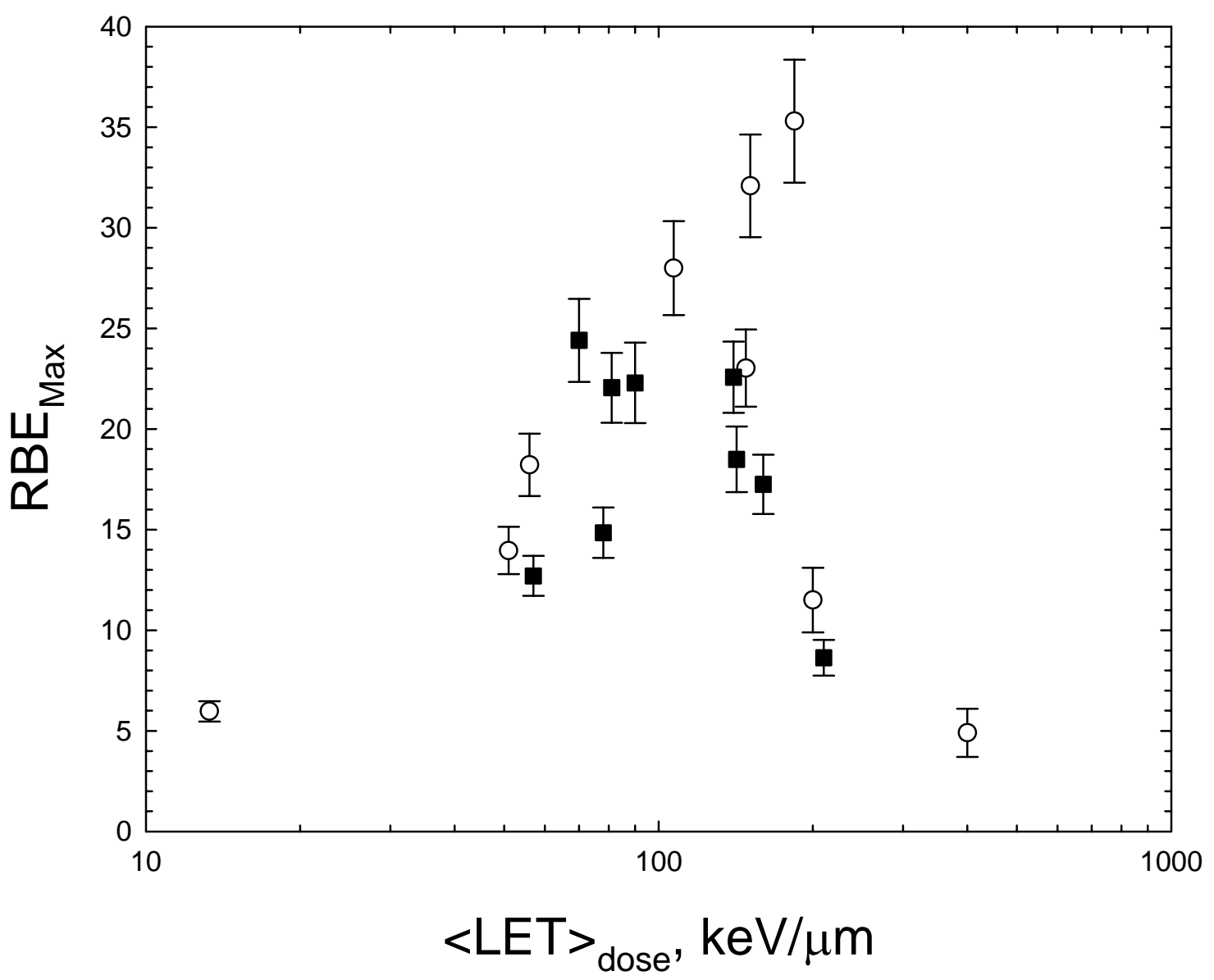

